\title{
ESTUDO SOBRE A CONDIÇÃO DE TREFILABILIDADE DE AÇO MÉDIO CARBONO PRODUZIDO EM ACIARIA ELÉTRICA *
}

João Vinícius Vares ${ }^{1}$

Afonso Reguly ${ }^{2}$

\begin{abstract}
Resumo
O presente trabalho apresenta um estudo acerca da trefilabilidade de arames de aço semelhante ao SAE 1045, que são destinados ao atendimento da demanda do setor agropecuário. $O$ trabalho envolveu a análise da produção dos arames a partir de matéria-prima advinda de aciaria elétrica, além das condições dos processos de conformação. O processo de trefilação foi mantido invariável, com as mesmas condições e parâmetros de reduções e lubrificação. Verificou-se a viabilidade de trefilação de ambos os materiais e a influência da maior fração volumétrica de perlita, através de análises conjugadas de propriedades mecânicas e condições microestruturais, resultando em valores mais elevados de resistência mecânica e menores valores de alongamento para os arames.
\end{abstract}

Palavras-chave: Arames; Fração perlítica; Trefilabilidade.

\section{EVALUATION OF THE STEEL WIRE DRAWABILITY OF MEDIUM CARBON STEEL PRODUCED IN ELECTRIC ARC FURNACE}

\begin{abstract}
This work presents a study on the wire drawing of modified SAE 1045 steels, which are designed to meet the demand of the agricultural sector. The work involved the analysis of the production of the wires from the raw material coming from EAF steel making, and the wire drawing processes. The wire drawing process was kept constant. It was verified the viability of drawing of both materials and the influence of the greater volumetric fraction of perlite, through conjugated analyzes of mechanical properties and microstructural conditions, resulting in higher values of mechanical resistance and lower values of elongation for the wires.
\end{abstract}

Keywords: Steel wire, pearlite fraction, drawability.

1 Engenheiro Metalúrgico, Mestre, Doutorando em Engenharia, Laboratório de Corrosão, Proteção e Reciclagem de Materiais - PPGE3M/UFRGS, Av. Bento Gonçalves, 9500, Porto Alegre, Brasil.

2 Engenheiro Metalúrgico, Doutor, Professor Titular, Laboratório de Metalurgia Física (LAMEF) PPGE3M/UFRGS, Av. Bento Gonçalves, 9500, Porto Alegre, Brasil. 


\section{INTRODUÇÃO}

\subsection{Produção de arames}

As aplicações possíveis para arames de aço são as mais diversas, podendo ter emprego na indústria mecânica, da construção civil e na agropecuária. Essa diversidade de usos e aplicações se deve, principalmente, à enorme variedade dimensional e de propriedades mecânicas que se podem obter nos arames.

Os arames destinados ao setor agropecuário são, em sua maior parte, galvanizados e de alta resistência mecânica. Esses arames são utilizados em várias etapas e atividades do setor, desde o cercamento de propriedades e contenção de animais, como no cultivo de fruticulturas que necessitam de sustentação e condução - sendo os parreirais um exemplo claro dessa aplicação, conforme mostra a Figura $1 \mathrm{com}$ desenho esquemático e imagem da aplicação real.

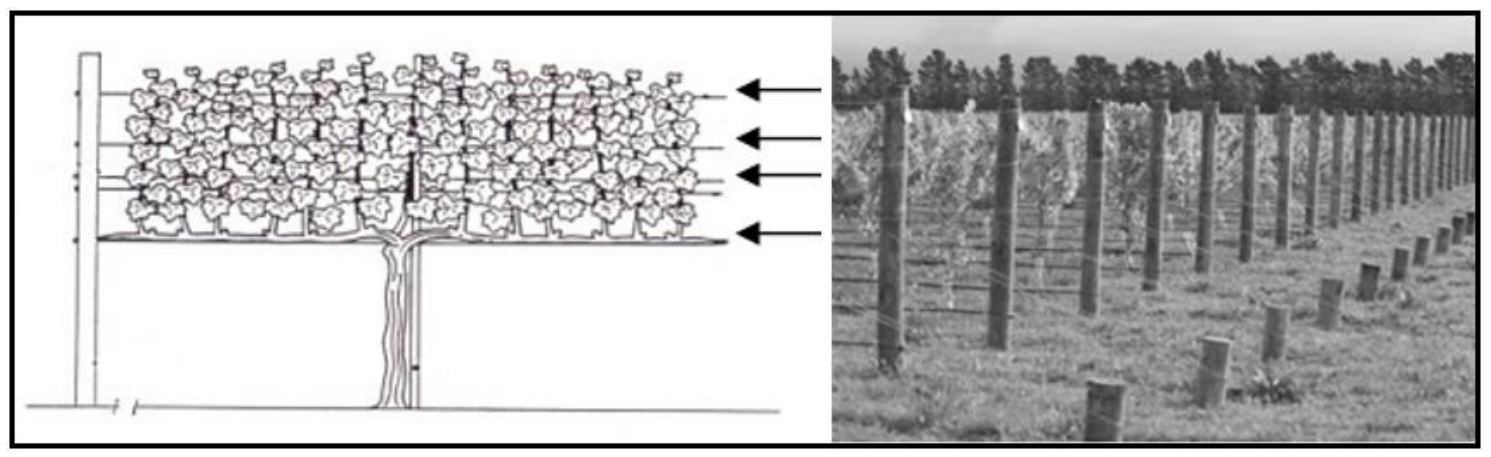

Figura 1 Sistema de condução da videira em espaldeira; indicadas pelas setas as posições dos arames. [1]

A fabricação de arames pode se dar em usinas siderúrgicas (desde a produção do aço) ou em unidades que realizam apenas a etapa de conformação mecânica Trefilação. O processo em uma usina siderúrgica tem início pela obtenção do aço que será laminado em fio-máquina, um produto intermediário, que seguirá para o processo de trefilação, que dará origem aos fios de aço - arames [2]. Na Figura 2 é apresentado um fluxo esquemático dos estágios da produção de arames em uma usina siderúrgica.

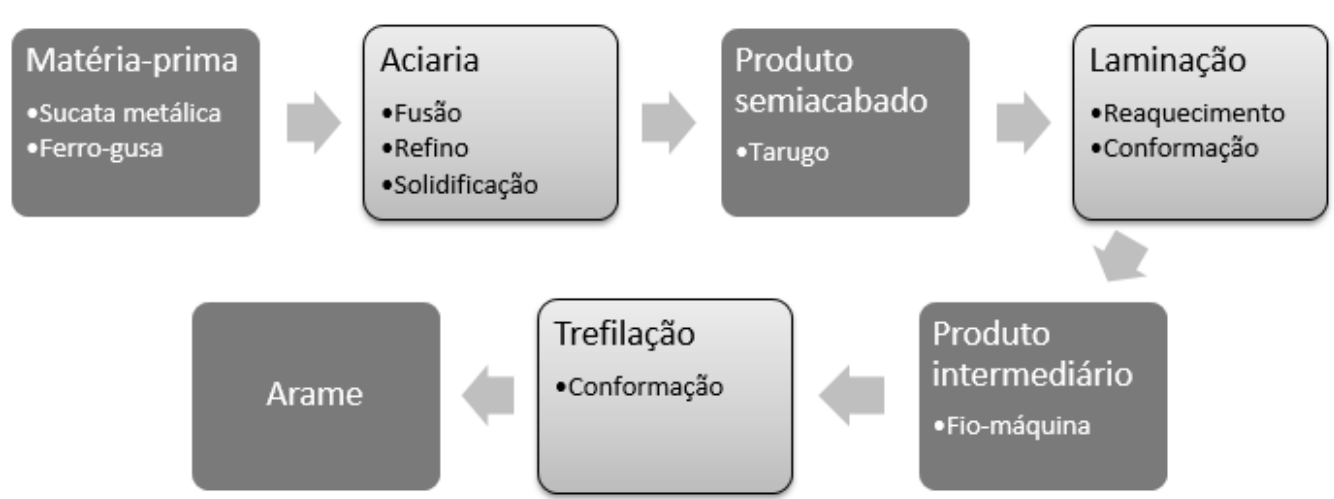

Figura 2 Fluxo esquemático da rota de produção de arames de aço em uma usina siderúrgica. 


\subsection{Processo de Trefilação}

A trefilação é a técnica de produzir fios ou barras pelo contínuo alongamento de um fio ou barra de maior diâmetro, obtido através da redução de área provocada pela passagem forçada do material por uma matriz de dimensão conhecida e controlada, mediante aplicação de esforço de tração na ponta do material que sai da matriz [3].

O processo de trefilação tem início com a decapagem (química ou mecânica) do fiomáquina, para a retirada de carepa, na sequência é colocado em uma máquina, onde começará a ser trefilado. Os tipos de máquinas possuem diferentes sequências de reduções, que são chamadas passes de trefilação. Em cada passe, o material sofre redução em área, até que no último passe lhe é conferido o diâmetro final [4].

A Figura 3 ilustra o processo de trefilação com fieira, que é muito comum para a produção de arames a partir de fio-máquina, produzido por laminação a quente.

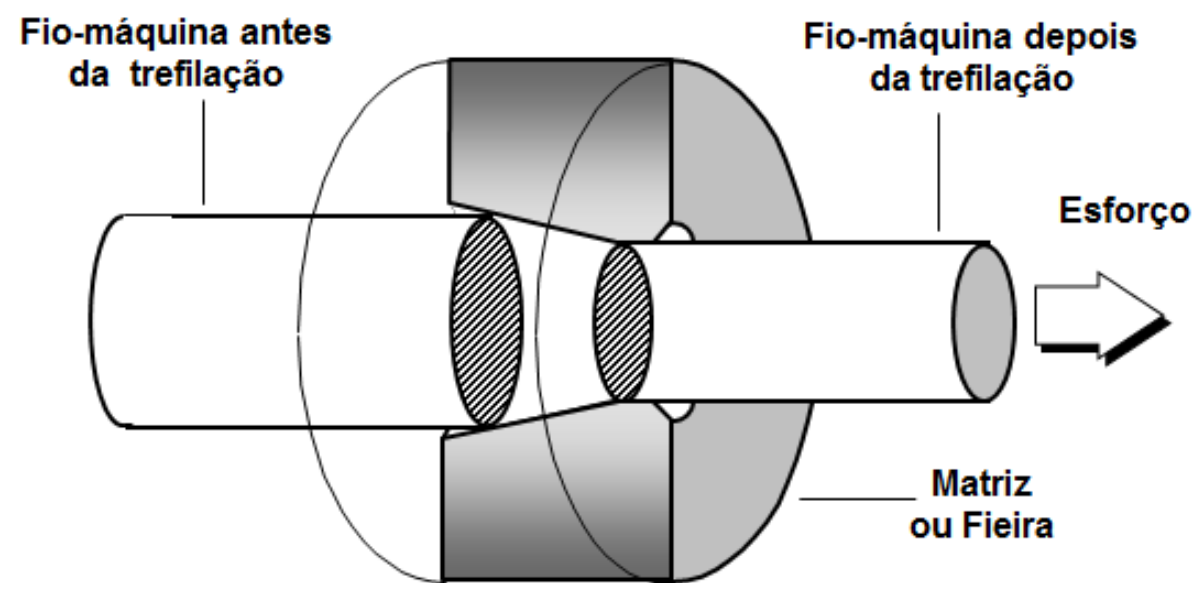

Figura 3 Representação esquemática do processo de trefilação com fieira a partir de fio-máquina.

O processo tradicional de trefilação com fieiras impõe reduções de seção muito grandes, o excesso de atrito segura o material e o traciona, causando estiramento e grande geração de calor. Por essas razões é necessário um sistema de refrigeração em cada fieira, bem como lubrificação do material sendo trefilado, para evitar que o calor gerado pelo atrito entre a fieira e o material cause um aumento excessivo de temperatura - que causa diminuição da vida útil da ferramenta, prejudica a lubrificação e as propriedades finais do produto [5].

\subsection{Mecanismos para ganho de resistência}

De acordo com as aplicações a que são destinados os aços e as exigências quanto às suas propriedades mecânicas, torna-se necessário o emprego de técnicas que possibilitem a otimização dessas propriedades. 
Os mecanismos mais explorados, tanto pela viabilidade técnica quanto econômica, são: solução sólida, endurecimento por deformação plástica a frio, refino de grão, tratamento térmico e endurecimento por partículas de segunda fase.

$\mathrm{Na}$ produção de arames o mecanismo preponderante é o endurecimento por deformação plástica a frio - encruamento.

\subsubsection{Endurecimento por Deformação Plástica a Frio}

É o fenômeno pelo qual um metal dúctil se torna mais duro e mais resistente quando é submetido a uma deformação plástica. Pelo fato da deformação ser realizada abaixo da temperatura de recristalização, diz-se que é um trabalho a frio.

O encruamento é explicado com base em interações entre os campos de deformação das discordâncias. A densidade de discordâncias em um metal aumenta com a deformação ou o trabalho a frio, devido à multiplicação das discordâncias ou à formação de novas. Como consequência, tem-se que a distância média de separação entre as discordâncias diminui - elas ficam posicionadas mais próximas umas das outras. $\mathrm{Na}$ média, as interações discordâncias-deformações de discordâncias são repulsivas. O resultado global é tal que o movimento de uma discordância é dificultado pela presença das demais. Na medida em que se eleva a densidade de discordâncias, a resistência ao movimento se torna, cada vez mais, pronunciada. Assim, a tensão imposta, necessária para deformar um metal, aumenta com o aumento do trabalho a frio [6].

O endurecimento por deformação plástica a frio é amplamente empregado na produção de arames de aço, pois é o mecanismo inerente ao processo de trefilação, em que ocorre a deformação plástica do material - havendo a redução da seção transversal e, simultâneo e consequente, aumento do comprimento [7].

\section{MATERIAIS E MÉTODOS}

Os lotes dos aços com as composições utilizadas neste trabalho, denominadas AEL 1 e AEL 2, tiveram origem em uma usina siderúrgica semi-integrada, dotada de uma aciaria com forno elétrico a arco, que utiliza sucata metálica como matéria-prima principal. Os acertos necessários de composições químicas e de temperatura foram realizados em um forno-panela. Logo após, o aço líquido passou pela etapa de lingotamento contínuo, onde foram produzidos os tarugos - a matéria-prima para a laminação do fio-máquina e posterior trefilação dos arames.

Os tarugos foram direcionados para a laminação do fio-máquina, passando por um forno de reaquecimento, no qual atingiram temperaturas próximas a $1100^{\circ} \mathrm{C}$. Depois disso, os tarugos passaram por um trem de laminação composto por 24 passes, sendo que os últimos 10 passes ocorreram em um bloco laminador. $O$ trem de laminação é dividido em desbaste, onde ocorrem grandes reduções; trem médio, início das diferentes regulagens para as diversas bitolas; e por fim o bloco acabador, que confere a forma e o dimensional necessários para o fio-máquina, que no presente trabalho é o dimensional de $5,50 \mathrm{~mm}$. 
Ao passar pelo último passe no bloco laminador, o fio-máquina adquiriu sua forma final. Em seguida, o material passou por uma zona de resfriamento, na qual água sob pressão é utilizada para reduzir a temperatura para um valor em torno de $950^{\circ} \mathrm{C}$. O resfriamento é necessário para que ocorra a formação correta das espiras de fiomáquina.

A formação das espiras se dá por um equipamento que impõe uma curvatura em alta velocidade ao fio-máquina, que serão coletadas pelo coletor de espiras, formando rolos que caem sobre uma esteira, na qual o material segue resfriando ao ar, com a possibilidade de alteração das taxas de resfriamento - com o emprego de ventiladores ou capotas abafadoras, por exemplo. Na sequência, o material depois de prensado, é amarrado, pesado e identificado.

Por fim, o fio-máquina é destinado à trefilação, para produção dos arames de aço e posterior processo de galvanização. O processo de conformação mecânica se dá em uma trefila com máquinas dotadas de decapagem mecânica, por flexão e lixas rotativas, e que utilizam fieiras como matrizes - que possibilitam grande precisão e controle dimensional e superficial. Para 0 arame em estudo, foi utilizada uma sequência de reduções composta de sete passes e lubrificantes sólidos a base de cálcio e sódio para se chegar ao dimensional de $2,10 \mathrm{~mm}$, partindo do fio-máquina $5,50 \mathrm{~mm}$.

Após a trefilação os arames seguiram para o processo de galvanização, que ocorre em uma linha contínua, onde passa pelas etapas de desengraxe, decapagem química, lavagem, fluxagem, galvanização e passivação. Ao final, a etapa de bobinamento, em que o material é acondicionado em embalagens convenientes a cada aplicação (rolos).

\subsection{Composição química}

Os resultados de composições químicas foram obtidos a partir de amostras retiradas diretamente dos fios-máquina. Os ensaios foram realizados via espectrometria de emissão óptica, com o equipamento ARL 3460 AES.

\subsection{Análise microestrutural}

A caracterização dos fios-máquina e dos arames foi feita a partir de amostras de seções transversal e longitudinal, respectivamente.

Para revelar a microestrutura foi feito ataque das superfícies com reagente Nital $2 \%$. A aquisição das imagens obtidas foi realizada com auxílio de um microscópio óptico OLYMPUS BX60M acoplado a uma câmera digital DXC-970MD e um sistema de aquisição de imagens por computador.

Também foram feitas análises em um microscópio eletrônico de varredura SHIMADZU SSX-550.

\subsection{Ensaio de tração}

Os ensaios de tração foram conduzidos em conformidade com a norma ABNT NBR ISO 6892-1:2013. A máquina EMIC DL10000, com capacidade de 10t, foi eleita para realização dos ensaios. 
A partir desses ensaios foi possível obter valores de limite de escoamento, limite de resistência, carga de ruptura, alongamento após a ruptura e estricção.

\section{RESULTADOS E DISCUSSÃO}

\subsection{Composição química}

Os teores de carbono, manganês e silício da condição AEL 1 ficaram bastante próximos dos limites mínimos da especificação proposta. Por outro lado, para a condição AEL 2, objetivou-se ficar próximo dos limites máximos da especificação proposta.

As composições químicas das qualidades propostas são apresentadas na Tabela 1.

Tabela 1 Composição química das condições analisadas

\begin{tabular}{cccccccccc}
\hline \multicolumn{10}{c}{ Composição Química [\%] } \\
\hline & $\mathbf{C}$ & $\mathbf{M n}$ & $\mathbf{S i}$ & $\mathbf{S}$ & $\mathbf{P}$ & $\mathbf{C r}+\mathbf{C u}+\mathbf{N i}$ & $\mathbf{M n} / \mathbf{S}$ & $\mathbf{M n} / \mathbf{S i}$ & $\mathbf{C e q}[\%]$ \\
\hline AEL 1 & 0,43 & 0,63 & 0,19 & 0,02 & 0,02 & 0,25 & 34 & 3 & 0,57 \\
\hline AEL 2 & 0,46 & 0,81 & 0,29 & 0,02 & 0,02 & 0,24 & 51 & 3 & 0,62 \\
\hline
\end{tabular}

\subsection{Análise microestrutural}

Foram selecionadas micrografias representativas dos materiais a serem analisados, nas condições AEL 1 e AEL 2 dos fios-máquina, com o intuito de determinar as frações presentes e, a partir desses dados, buscar relacionar com os resultados de propriedades mecânicas.

Para a determinação da fração volumétrica em metais, considera-se, em geral, que essa é igual à fração em área. Pelo fato da opacidade dos metais, não se tem acesso ao volume, para o que seria necessária a obtenção de sucessivas seções do material, em uma espécie de tomografia, o que é demasiado trabalhoso e demorado [8].

Pela preparação da imagem foi possível realizar a medição das áreas e chegar aos valores de fração de volume dos microconstituintes.

Nas Figuras 4 e 5 tem-se as micrografias das condições AEL 1 e AEL 2, respectivamente. 


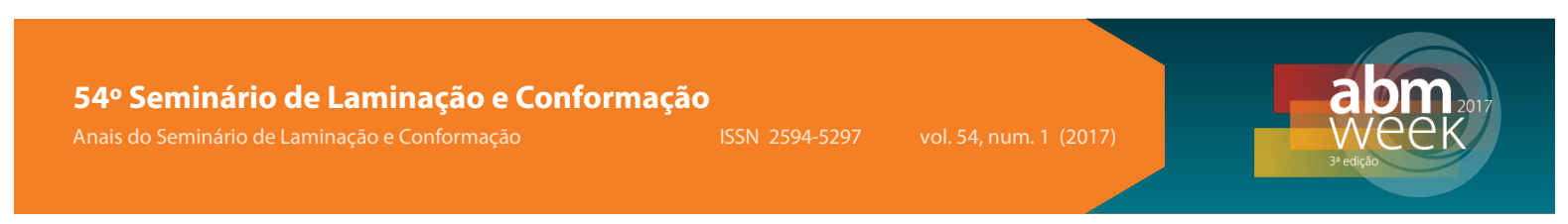

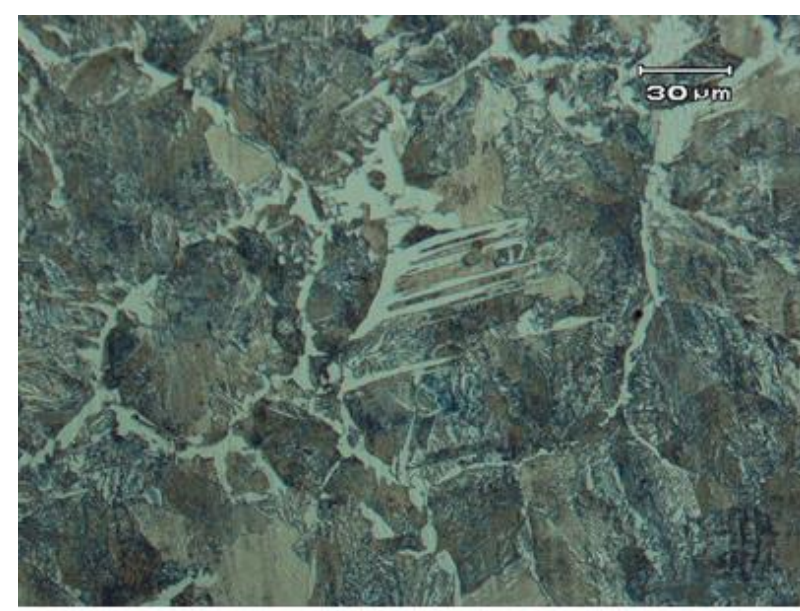

(a)

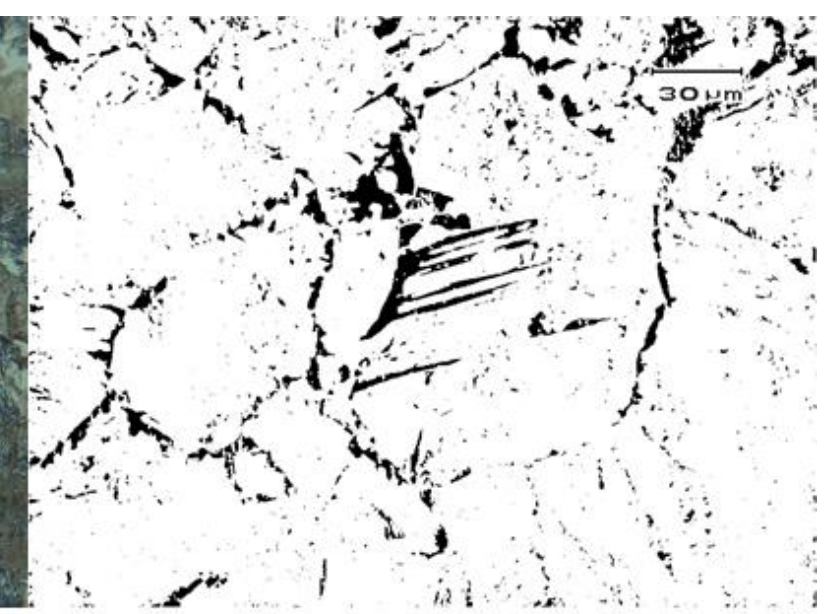

(b)

Figura 4

(a) Microestrutura da seção transversal de uma amostra de fio-máquina do aço AEL 1, revelada a partir de ataque Nital 2\% e com aumento de 500X; (b) imagem tratada em software

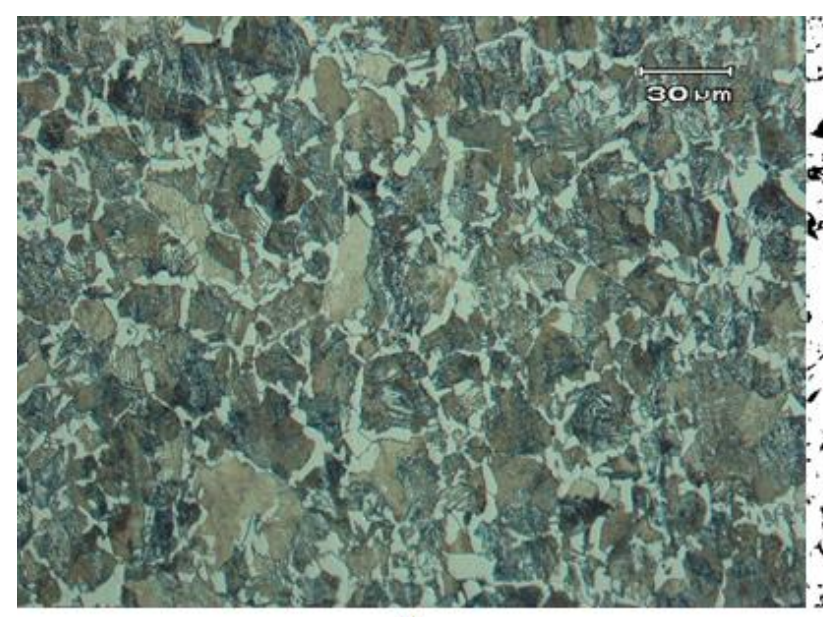

(a)

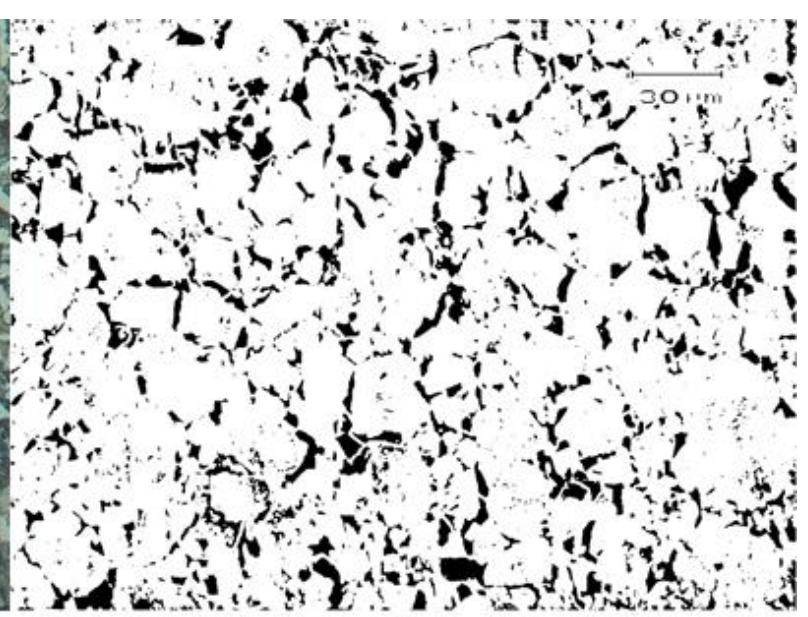

(b)

Figura 5

(a) Microestrutura da seção transversal de uma amostra de fio-máquina do aço AEL 2, revelada a partir de ataque Nital 2\% e com aumento de 500X; (b) imagem tratada em software

A seguir na Tabela 2 são apresentados os resultados da determinação da fração volumétrica dos microconstituintes:

Tabela 2 Resultados de determinação da fração volumétrica dos microconstituintes

\begin{tabular}{cc}
\hline Condição & Fração volumétrica de ferrita [\%] \\
\hline AEL 1 & 8,57 \\
\hline AEL 2 & 14,50 \\
\hline
\end{tabular}

A partir dos resultados de determinação da fração volumétrica, realizada por meio de software de análise de imagens, verificou-se que a condição AEL 1 é a que apresenta a menor fração de ferrita pró-eutetóide em sua microestrutura - tendo, portanto, predominância de perlita em sua microconstituição. 
Além das micrografias obtidas por microscopia óptica, também foi utilizada microscopia eletrônica de varredura para avaliação do espaçamento interlamelar da perlita - Figura 6 - presente em cada uma das amostras.

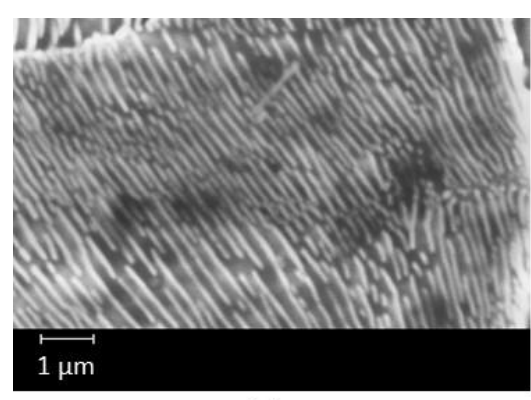

(a)

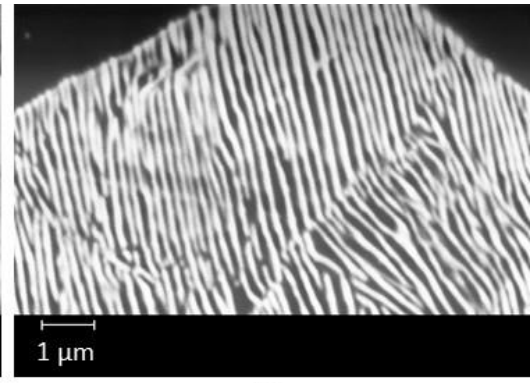

(b)

Figura 6 Micrografias obtidas através de microscopia eletrônica para determinação do espaçamento interlamelar nas amostras AEL 1 (a) e AEL 2 (b)

Conforme abordado por Silva [9], o espaçamento interlamelar da perlita, em uma determinada amostra a uma determinada temperatura, é constante, não variando consideravelmente em relação a um valor médio. Razão essa, pela qual, assume-se esse valor médio como referência.

$\mathrm{Na}$ Tabela 3 são apresentados os valores de espaçamento interlamelar médio da perlita para cada uma das condições avaliadas:

Tabela 3 Resultados de determinação do espaçamento interlamelar da perlita

\begin{tabular}{cc}
\hline Condição & Espaçamento interlamelar médio $[\mu \mathrm{m}]$ \\
\hline AEL 1 & 0,16 \\
\hline AEL 2 & 0,22 \\
\hline
\end{tabular}

Observou-se similitude entre os valores de espaçamento determinados para as condições AOX e AEL 2, tendo a condição AEL 1 apresentado um espaçamento médio relativamente menor - 0 que se pode depreender de uma maior taxa de resfriamento no formador de espiras na laminação do fio-máquina, conforme Silva [9].

\subsection{Ensaio de tração}

As Figuras 7 e 8 mostram os resultados obtidos para as amostras de ambos os fiosmáquina, condições AEL 1 e AEL 2, para efeitos de comparação. 


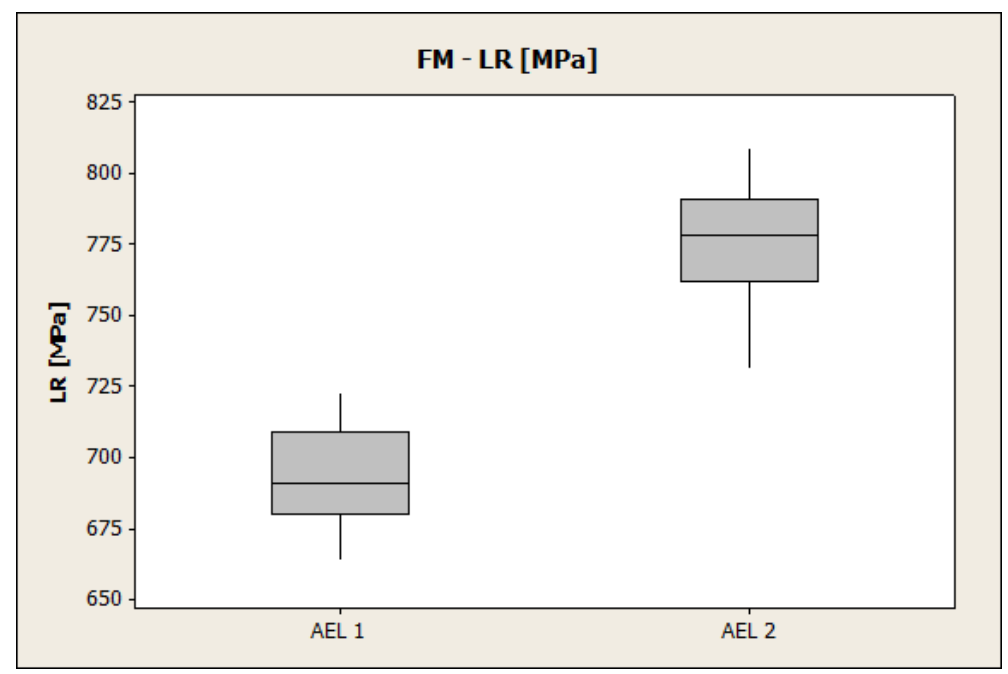

Figura 7

Limite de resistência dos fios-máquina das condições AEL 1 e AEL 2

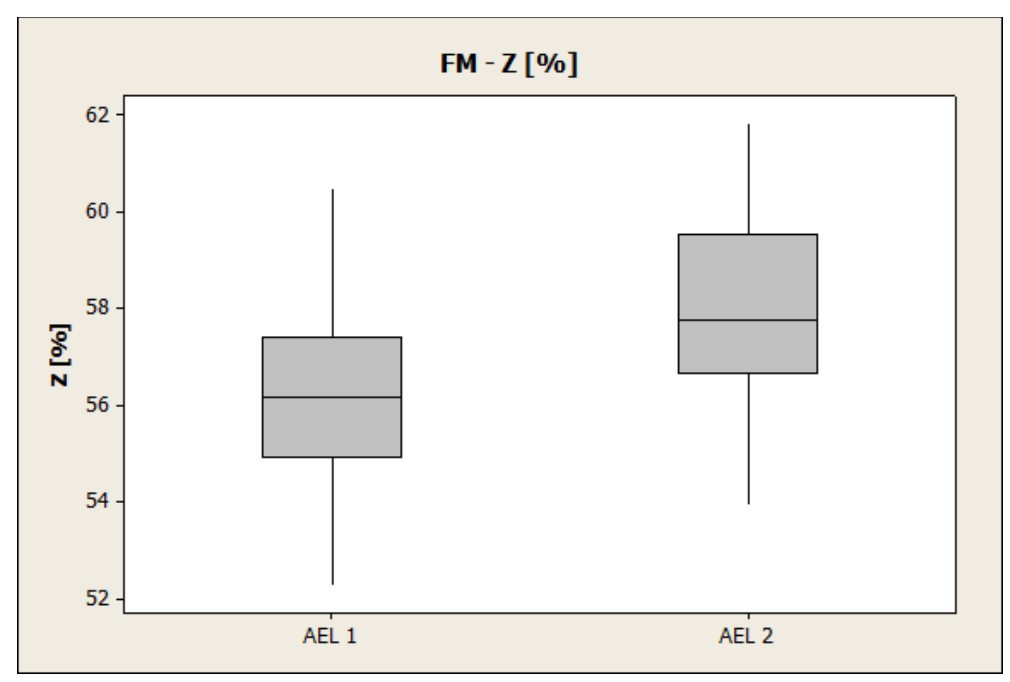

Figura 8

Estricção dos fios-máquina das condições AEL 1 e AEL 2

Com relação às propriedades mecânicas, o fio-máquina da condição AEL 2 apresenta valores maiores para LR, principalmente por seu maior teor de carbono frente a condição AEL 1.

A seguir, nas Figuras 9 a 11, são exibidos os resultados de propriedades mecânicas - LR, CRup e ALNG - para os arames AEL 1 e AEL 2. 


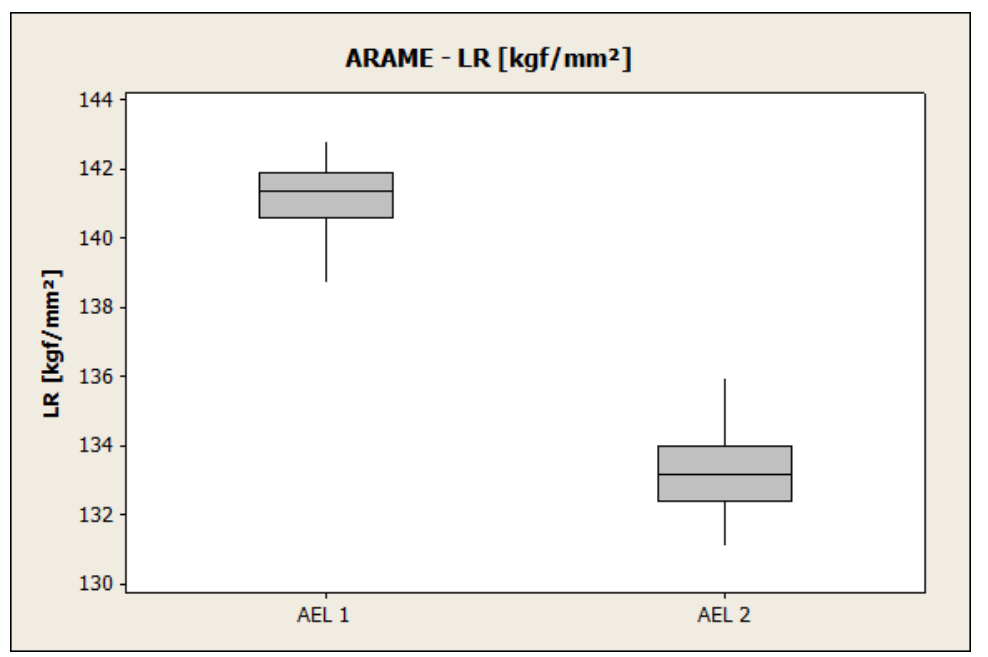

Figura 9

Limite de resistência dos arames produzidos a partir dos aços AEL 1 e AEL 2

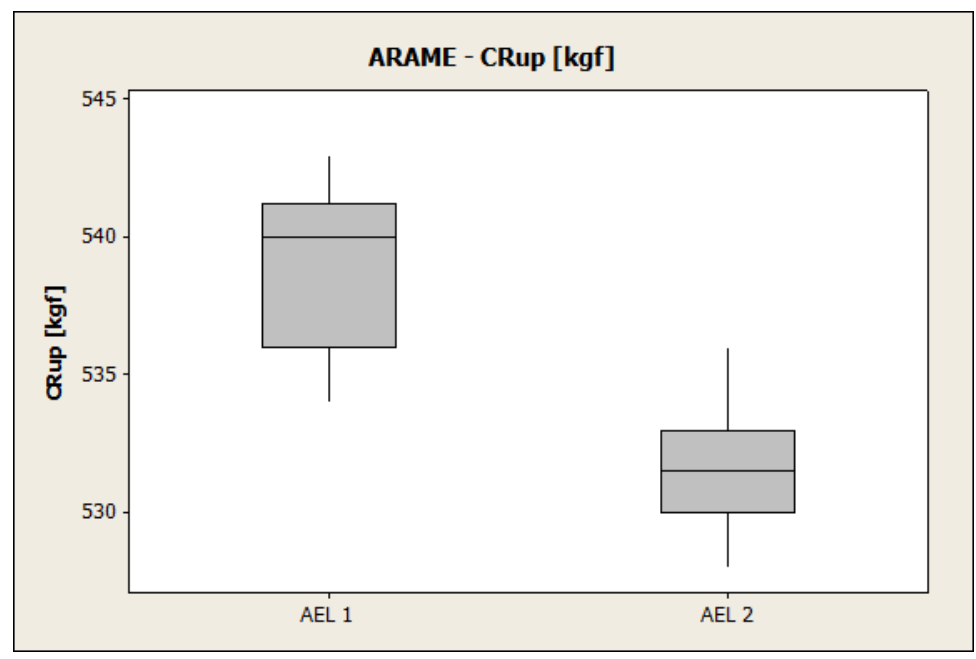

Figura 10 Carga de ruptura dos arames produzidos a partir dos aços AEL 1 e AEL 2

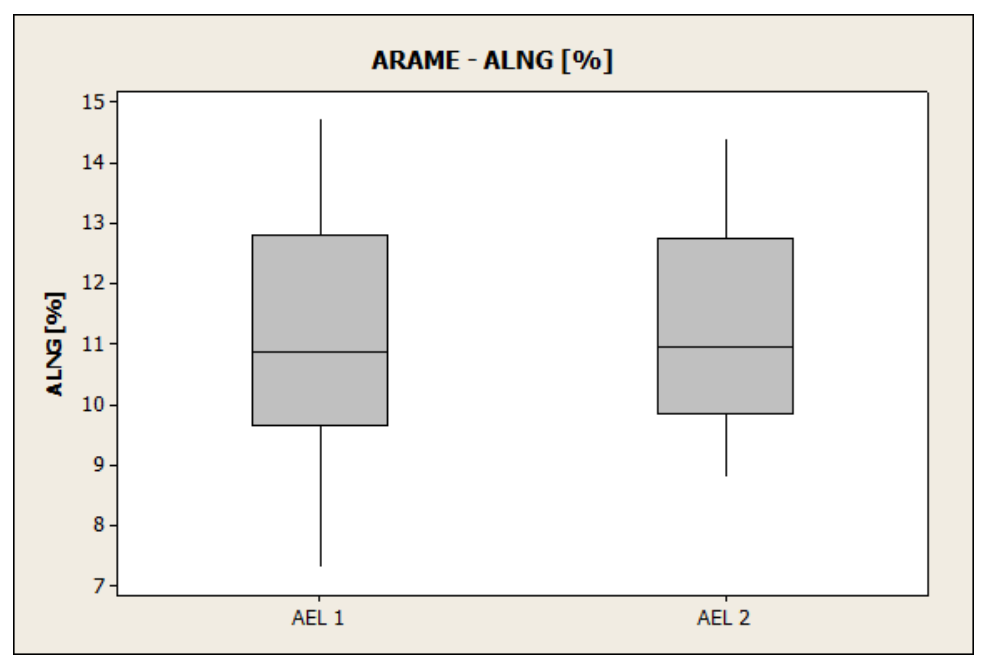

Figura 11 Alongamento dos arames produzidos a partir dos aços AEL 1 e AEL 2 
O endurecimento promovido pela deformação plástica a frio, durante o processo de trefilação, resulta em diferentes níveis de encruamento em função da microestrutura prévia - maior ou menor fração de perlita, que é um microconstituinte de maior dureza, quando comparado com a ferrita [7].

\section{CONCLUSÃO}

Com base nos resultados dos ensaios de tração, restou evidenciado que os arames da condição AEL 1 foram os que apresentaram os maiores valores de resistência mecânica - LR e CRup. Tal situação não foi observada nos resultados referentes ao fio-máquina, em que a condição AEL 2 é que apresentou os maiores valores para tais propriedades.

O menor espaçamento interlamelar médio da perlita da condição AEL 1 pode ser considerado fator positivo para sua trefilabilidade nos processos posteriores.

\section{Agradecimentos}

Agradecemos à Gerdau Riograndense por proporcionar as condições necessárias ao desempenho dos trabalhos.

\section{REFERÊNCIAS}

1 EMBRAPA UVA E VINHO. Sistemas de Condução da Videira. [acesso em 15 set. 2016].Disponível em: http://www.cnpuv.embrapa.br/publica/sprod/viticultura/espald.html.

2 ARAUJO, L. A. Manual de Siderurgia. 2009; Vol. 2.

3 BUTTON, S. T. Trefilação: Programa de Educação Continuada. São Paulo: ABM; 2001.

4 DOVE, A. B. Steel Wire Handbook. USA: The Wire Association INC, Vol 1, 3ed; 1979.

5 EL-DOMINATY, A.; KASSAB, S. Z. Temperture Rise in Wire-Drawing. Journal of Materials Processing Technology, Vol 83; 1998.

6 GLADMAN, T. The Physical Metallurgy of Microalloyed Steels. 1ed. London: The Institute of Materials; 1997.

7 CETLIN, P. R. Trefilação Básica. Depto de Engenharia Metalúrgica e de Materiais. Belo Horizonte: UFMG; 2002.

8 LOMBARDO, S. et al. Método para o cálculo da fração volumétrica de austenita retida através do software de análise digital de imagens. Congresso Brasileiro de Engenharia e Ciência dos Materiais. 2010: p. 4968-4975.

9 SILVA, F. A. Efeito do resfriamento controlado após laminação a quente nas propriedades mecânicas e na microestrutura de um fio-máquina de aço alto carbono com cromo. Belo Horizonte: UFMG; 2007. 